\title{
Per Kilogram
}

National Cancer Institute

\section{Source}

National Cancer Institute. Per Kilogram. NCI Thesaurus. Code C120844.

A mass unit equal to one kilogram used as a denominator to build a derived unit expressed as a ratio. 